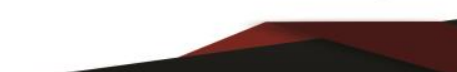

Artigo

\title{
Percepção dos Servidores Públicos Federais Sobre o Programa Nacional de Gestão Pública e Desburocratização - GESPÚBLICA
}

\author{
Miguel Lino Spinelli Rabelo Neto ${ }^{1}$; Raimundo Nonato Lima Filho ${ }^{2}$
}

\begin{abstract}
Resumo: Este artigo tem como objetivo identificar a percepção dos servidores públicos federais a respeito do Programa Nacional de Gestão Púbica e Desburocratização - Gespública, do seu início no ano de 2005 até sua revogação no ano de 2017, também serão apresentados noções de Administração Pública Gerencial, examinando seus antecedentes e enfatizando a condição de mudança necessária para a Administração Pública Brasileira, que tem como seu papel receber tributos e aplicá-los de forma eficiente e que tragam a efetividade para a sociedade. Por fim trataremos sobre questões a respeito do futuro da Administração Pública Brasileira e quais as suas perspectivas.
\end{abstract}

Palavras-chave: Gespública, Administração Pública Gerencial, Gestão Pública, Eficiência, Efetividade.

\section{Perception of Federal Public Servants on the National Program of Public Management and un Bureaucracy - GESPÚBLICA}

\begin{abstract}
The article aims to identify the perception of federal public servants regarding the National Public Management and un Bureaucracy Program - Gespública, from its beginning in 2005 until its revocation in 2017, also will be presented notions of Public Management, examining its antecedents and emphasizing the necessary change condition for the Brazilian Public Administration, whose role is to receive taxes and apply them efficiently and that bring effectiveness to society. Finally, we will discuss questions about the future of the Brazilian Public Administration and its perspectives.
\end{abstract}

Keywords: Gespública, Public Administration, Public Management, Efficiency, Effectiveness.

\footnotetext{
${ }^{1}$ Graduação pela Universidade Federal de Alagoas. Concluinte do Curso de Especialização em Gestão Pública pela Universidade Federal do Vale do São Francisco - UNIVASF. Administrador do Instituto Federal Baiano, campus Guanambi. Contato: mlsrneto@gmail.com;

${ }^{2}$ Doutor em Controladoria e Contabilidade pela Universidade de São Paulo (USP) e Doutor em Administração pela Universidade Federal da Bahia (UFBA), possui Pós-Doutorado pela Universidade Federal da Paraíba (UFPB). É Professor da Autarquia Educacional do Vale do São Francisco (AEVSF). Pesquisador dos grupos de pesquisa: Grupo de Estudos de Tecnologia da Educação na Contabilidade (USP), Contabilidade e Controladoria (UFBA), Laboratório de Pesquisa em Contabilidade de Gestão (UFBA), Núcleo de Estudos em Contabilidade Financeira e Finanças Empresariais (UFBA) e Grupo de Pesquisa em Finanças e Contabilidade (UFPB). Contato: rnlfilho@gmail.com.
} 


\section{Introdução}

No contexto atual do nosso país a Administração Pública está cada vez mais sendo exigida e combatida, devido à má gestão do erário e dos bens públicos e também pela enorme dificuldade de se prestar um serviço digno aos cidadãos do Brasil, ou seja, a Administração Pública está se mostrando ineficiente e não está realizando seu trabalho de uma forma correta.

Mas isso não se iniciou no presente momento, já é algo que vem sendo debatido a algum tempo e que se tornou um grande obstáculo a ser enfrentado pela Administração Pública, que tenta buscar alternativas para dirimir esta situação, criando mecanismos para conter esse problema. Dentre um dos mecanismos criado pela Administração Pública e que teve grande destaque pelo impacto que seria gerado foi o Programa Nacional de Gestão Pública e Desburocratização - Gespública através do Decreto 5378/2005 sendo instituído pelo então Presidente da República Luiz Inácio Lula da Silva.

Este decreto era um modelo gerencial para ser aplicado na Administração Pública e conforme seu artigo $2^{\circ}$ elencava os seguintes objetivos: eliminar o deficit institucional; promover a governança; promover a eficiência; assegurar a eficácia e efetividade da ação governamental e promover a gestão democrática, participativa, transparente e ética.

Com isso fica claro que a Administração Pública possuía meios para melhorar a sua eficiência, eficácia e efetividade, mas que na verdade o grande problema era como implantar esta ferramenta, pois mesmo o decreto indicando que órgãos e instituições públicas poderiam implantar a Gespública por adesão ou convocação, muito pouco foi feito para garantir que ela chegasse à Administração Pública como um todo.

O reflexo disso foi a revogação do Decreto 5.378/2005 pelo Decreto 9.094/2017, que dispõe sobre: "a simplificação do atendimento prestado aos usuários dos serviços públicos, ratifica a dispensa do reconhecimento de firma e da autenticação em documentos produzidos no País e institui a Carta de Serviços ao Usuário”, ou seja, o Programa Gespública, foi substituído por um decreto de simplificação documental, somente aproveitando do Programa Gespública: a carta de serviços do cidadão.

Portanto a ideia deste trabalho é entender o impacto que essas mudanças trarão para o serviço público, também conhecer o pensamento e como os servidores enxergam o gerencialismo no serviço público, para isso serão abordadas questões referentes ao conhecimento destes servidores a respeito do Programa Nacional de Gestão Pública e 
Desburocratização - Gespública e sobre os benefícios que o programa poderia ter trazido caso tivesse sido empregado em sua plenitude. Essas questões serão importantíssimas para a pesquisa pois será possível identificar se existe dentro do serviço público um engajamento e identificação com técnicas e métodos do gerencialismo.

O Objetivo deste trabalho é sobre a percepção Servidores Públicos federais do Programa Gespública, sua revogação e quais as consequências que isso trará para a Administração Pública, também analisaremos a postura destes servidores com relação à Administração Pública Gerencial.

\section{Fundamentação Teórica}

A Administração tornou-se uma das mais importantes áreas da atividade humana, sendo a chave para a solução dos mais graves problemas que atualmente atingem a humanidade, utilizando para dirimir esses problemas, a tecnologia e o capital intelectual, pois conforme Chiavenato (2000), "a tarefa básica da Administração é fazer as coisas por meio das pessoas de maneira eficiente e eficaz".

A Administração como ciência das organizações tem um papel bastante peculiar quando se trata do que é público, nesse sentido a Administração apresenta algumas características que acabam diferenciando a Administração Pública da Particular, tais como: a Administração pública é executora, instrumental, autônoma, neutra e dependente no sentido de decisões governamentais. A Administração Pública precisa respeitar leis, normas e princípios que limitam suas atuações.

Mas nem sempre foi dessa forma nos primórdios da Administração Pública e atuando de forma totalmente desorganizada o modelo patrimonialista foi o primeiro ensaio do que era Administração e uma de suas características era a não distinção entre o que era bem público e o que era bem particular, existia um líder soberano que ditava o que poderia ser feito com os bens públicos, quem poderia ser nomeado para trabalhar no serviço público, descaracterizando divisão de trabalho, meritocracia, favorecendo àqueles que se apresentavam como pessoas de confiança e que eram subservientes aos seus comandos e devaneios.

Com isso abria espaço para a corrupção e nepotismo dentro do serviço público e demonstrando que o Estado não agia de forma coletiva nem tinha como prioridade atender aos 
anseios e necessidades da população, mas sim do soberano que estivesse no poder. Para Paludo (2016) a Administração Patrimonialista possui as seguintes características que valem a pena destacar: "Confusão entre a propriedade pública e a particular, impermeabilidade à participação social-privada, endeusamento do soberano, caráter discricionário e arbitrário das decisões, ausência de carreiras administrativas, poder oriundo da tradição/hereditariedade.

Este modelo de Administração Pública vigorou em países com democracias imperfeitas, como o Brasil, por muito tempo, mas devido a revolução industrial e também o aparecimento de grandes organizações, foi necessário adotar um modelo de Administração que se mostrava o oposto do modelo patrimonialista, o modelo se chamava burocracia, ou ainda, Administração Pública Burocrática.

A Administração Pública Burocrática surgiu com a missão de acabar com a corrupção e o nepotismo patrimonialista, que conforme Bresser-Pereira (1996), "a administração pública burocrática foi adotada para substituir a administração patrimonialista, que definiu as monarquias absolutas, na qual o patrimônio público e o privado eram confundidos”, também era necessário um novo modelo de administração já que o modelo anterior encontrava-se desgastado, principalmente por ser um modelo que só trouxe desorganização ao Estado, tanto na prestação do serviço público, quanto na falta de um projeto de desenvolvimento para o país.

Dentro dessas questões temos que, segundo Paludo (2016), a Administração Pública Burocrática possui as seguintes características: "respeito à hierarquia, profissionalização, meritocracia, padronização, formalismo, impessoalidade, sintetizando: o poder racional-legal". Essas características dizem muito sobre o funcionamento desse modelo de Administração e que através delas muitas mudanças e novos conceitos foram trazidos para a Administração Pública e uma das mais significantes foi a separação entre o público e o privado, através de regras prédefinidas, reestruturação e reorientação da Administração, para atender às crescentes demandas da população.

No Brasil a Administração Púbica burocrática esteve relacionada diretamente através de duas fases, sendo a primeira da era Vargas e a segunda a partir do governo de Juscelino Kubitschek até o início da reforma gerencial. Contudo com a modernização e a necessidade de acompanhar o crescimento dos países desenvolvidos a burocracia foi perdendo força, principalmente devido às disfunções que ela apresentou, tal como, a resistência às mudanças, formalismo exagerado, rigidez, impessoalidade exagerada, apego a regulamentos internos. 
Com isso foi necessário avançar em busca de um modelo de Administração que pudesse atender a essas novas demandas da sociedade, que estava cada vez mais exigente e atenta as suas necessidades e este modelo teria a missão de trazer competitividade e eficiência à Administração Pública, sendo necessário buscar a excelência na administração e esse modelo é conhecido Administração Pública Gerencial, que segundo Chiavenato (2008) "a Administração Pública Gerencial constitui um avanço e, até um certo ponto, um rompimento com a Administração Pública Burocrática”.

Com a mudança do mundo e de tudo que surgiu com o advento de tecnologias e desenvolvimento, a Administração Pública também precisou se adaptar a essas mudanças e isso aconteceu através da introdução do modelo de Administração Pública gerencial, no Brasil a "pedra fundamental" foi a reforma gerencial que teve como principal fonte o Plano Diretor de Reforma do aparelho do Estado de 1995, que tinha como objetivos globais: Aumentar a capacidade administrativa de governar, através da governança, criar um limite com relação às funções que o Estado exerce como, por exemplo, deixar a produção de bens e serviços para a iniciativa privada, as ações locais deveriam ser transferidas para estados e municípios e só em casos emergenciais a União agiria, também seria necessário transferir para os estados ações de caráter regional através de parcerias entre estados e União.

Portanto podemos indicar que a Administração Pública gerencial se inspira na Administração de empresas privadas, conforme Vasconcelos Coutinho (2000), "o modelo de administração pública gerencial inspirou-se na administração privada, mas manteve uma distinção fundamental que é a defesa do interesse público". Mas não podemos confundir, já que as empresas vivem dos pagamentos que seus clientes efetuam na aquisição de um produto ou serviço e a receita do Estado advém de tributos, contribuições obrigatórias,

Além disso temos que existem muitas diferenças entre a Administração burocrática e a gerencial, enquanto a burocrática adotava o formalismo, a padronização e o interesse público no sentido do interesse do Estado, a Administração Pública gerencial entende que é preciso trazer dinamismo, eficiência e enxerga o interesse público, como sendo o interesse da coletividade e que o contribuinte seria como um cliente, onde é preciso atender suas necessidades e que conforme Vasconcelos Coutinho (2000): “a profunda transformação nas relações entre a administração pública e seus usuários deve-se, em grande medida, à crise do atendimento ao cidadão". 
Com isso temos que a Administração Pública gerencial promove princípios que até então nunca tinham sido vistos ou reconhecidos os quais devemos destacar: descentralização, profissionalismo, ética, foco no cidadão, eficiência, eficácia e efetividade, transparência e "accountability", tudo isso sendo utilizado para se alcançar uma alavancagem na produtividade e na qualidade na prestação dos serviços públicos, fazendo assim com que seus clientes/cidadãos sejam atendidos dentro de suas necessidades e possam também defender seus interesses.

Para fortalecer ainda mais esse pensamento em 2005 surge o Programa Nacional de Gestão Pública e Desburocratização - Gespública, que consiste justamente num modelo de excelência da Administração Pública, implicando a adoção de métodos e instrumentos de gestão adequados, eficazes e eficientes, que favoreçam o alcance de padrões elevados de desempenho e qualidade. Demonstrando que houve sim um modelo gerencial no Brasil, apesar de não ter sido empregado em sua plenitude.

Mas será que a Administração Pública Gerencial não possui falhas ou defeitos, com certeza possui defeitos, mas para Abrucio (1997): “em vez de se constituir em uma doutrina rígida e fechada, a Administração Pública Gerencial tem apresentado um grande poder de transformação, incorporando as críticas à sua prática, e assim modificando algumas peças de seu arcabouço", o que mostra sua flexibilidade com relação a possíveis mudanças e orientação para que possa enfrentá-las da melhor forma possível..

\section{Método}

A pesquisa teve como unidade de análise o grupo de servidores públicos federais que serão a referência norteadora para a mesma. A técnica de coleta de dados utilizada foi através de questionário descritivo/preferencial, onde se buscou descrever o perfil dos servidores participantes da pesquisa, bem como, descrevendo a problemática da referida pesquisa, sendo que o questionário eletrônico foi encaminhado via e-mail e através de redes sociais como: grupos de servidores públicos federais, nas mídias "Facebook" e "Whatsapp" e foram respondidos em sua totalidade de forma virtual, chegando a um total de 202 questionários respondidos. Também foi realizada uma pesquisa documental, onde foi realizada uma 
investigação em documentos externos (governamentais, de organizações não-governamentais ou instituições de pesquisa).

Já com relação à análise de dados foi utilizada a técnica quantitativa de análise de dados, através da estatística descritiva, onde apresentaremos os dados da pesquisa e também através da estatística inferencial que utilizaremos para identificar e caracterizar relações entre variáveis. $\mathrm{Na}$ análise foi realizada a explicitação dos dados, através de provação ou não das hipóteses e se o que foi apurado e verificado realmente se comprovaram ou não. Nessa fase percebemos as implicações das opiniões dos informantes com relação à Gespública e também sobre a importância ou não de uma Administração Pública Gerencial nas instituições onde os entrevistados exercem suas funções, verificando assim a percepção dos servidores públicos federais sobre o tema abordado. Além disso buscou-se reconhecer a percepção destes servidores com relação ao estilo de gestão empregado pela Administração Pública.

\section{Resultados}

\section{Sobre os entrevistados}

Foram entrevistados 202 servidores públicos federais de várias instituições, o questionário em si foi respondido de forma totalmente eletrônica, mas sem a identificação dessas instituições, para que isso não influenciasse nas respostas necessárias para o atendimento dos objetivos deste artigo. Mas ao mesmo tempo foi traçado o perfil dos entrevistados, isso é deveras importante porque o Programa Gespública teve seu decreto no ano de 2005 e sua revogação no ano de 2017, ou seja, teve uma duração de aproximadamente 15 anos e dentro do que é estabelecido nos seus objetivos e preceitos, já deveria ter sido implantado, fazendo parte da Administração Pública, por isso a importância em saber a idade, tempo de serviço público, escolaridade e se os mesmos já estiveram em algum cargo de confiança dentro da Gestão Pública, determinando o grau de conhecimento e envolvimentos destes servidores com o Programa Gespública.

Com relação a idade dos respondentes temos os seguintes resultados: 10,9\% dos entrevistados tem idade entre 18 e 28 anos, 50,5\% tem idade acima de 28 até 38 anos, 28,2\% possuem idade acima de 38 até 48 anos, já 7,9\% dos entrevistados possuem idade acima de 48 
até 58 anos e por último temos servidores acima de 58 anos que totalizam 2,5\% do total de entrevistados.

O próximo item com relação ao perfil dos entrevistados é o tempo no serviço público federal, onde os resultados apresentados foram: tempo de serviço entre 0 e 6 anos tendo o quantitativo de 40,6\% dos entrevistados, seguindo temos 38,1\% dos entrevistados possuem tempo de serviço público federal acima de 6 até 12 anos, adiante temos que 11,9\% tem tempo acima de 12 até 18 anos, seguindo foi verificado que 4,5\% dos entrevistados tem tempo de serviço público federal acima de 18 até 24 anos e finalizando 5\% dos entrevistados possuem mais de 24 anos no serviço público federal.

Seguindo com o perfil dos entrevistados será apresentado nesse momento o nível de escolaridade, onde foram colhidos os seguintes resultados: 5,4\% possuem ensino médio, 17,8 nível superior, 48,6\% especialização, 20,3\% dos entrevistados possuem mestrado e 7,9\% doutorado.

Para finalizar o entendimento sobre o perfil dos entrevistados foi perguntado também se eles já assumiram algum cargo de confiança ou função comissionada na Gestão Pública Federal e foi alcançado o seguinte resultado: 57,9\% informaram que "sim" e 42,1\% responderam que "não" assumiram nenhum cargo de confiança ou função comissionada na Gestão Pública Federal.

\section{Sobre as Instituições dos entrevistados.}

Apesar de não ter sido solicitado a informação onde os servidores entrevistados exercem suas atividades, todavia se faz necessário obter informações a respeito dessas Instituições para que seja verificado se existe alguma influência do Programa Gespública e se seus objetivos foram implementados, para que assim seja possível compreender sobre o processo de criação em 2005 e a descontinuidade do Programa Gespública no ano de 2017.

O primeiro questionamento sobre a instituição dos entrevistados é se eles acreditam que essas instituições são eficientes, $58,4 \%$ concordam parcialmente que a instituição onde trabalha é eficiente, sendo que $13,9 \%$ concordam plenamente sobre a eficiência de suas instituições, $3 \%$ dos entrevistados se mantiveram neutro sobre este assunto, já com relação aos que discordam, 19,3\% discordam parcialmente sobre a eficiência de suas instituições e 5,4 discordam 
totalmente sobre este tema. Com relação a eficiência, no decreto 5.378/2005 que institui o Programa Gespública, fica evidente a natureza de sua ação em seu artigo $2^{\circ}$, inciso III que é "promover a eficiência, por meio de melhor aproveitamento dos recursos, relativamente aos resultados da ação pública”, pois o Princípio da Eficiência que passou a integrar a legislação com a edição da Emenda Constitucional nº 19 de 1998 e que atribuiu a Administração Pública e seus agentes a busca do bem comum, por meio do exercício de suas competências de forma imparcial, neutra, transparente, participativa, eficaz, sem burocracia primando pela rentabilidade social.

Foi perguntado também se eles acreditam que suas instituições são transparentes em suas ações e atos, dentre os entrevistados 44,6\% que concordam parcialmente com esta afirmação e os que concordam plenamente foi um total de $14,9 \%$, os que se mantiveram neutro totalizaram $12,9 \%$ e os que discordaram parcialmente e discordaram plenamente com esta afirmação, totalizaram 17,8\% e 9,9\% dos entrevistados. A transparência também faz parte dos objetivos estabelecidos para o Programa Gespública, mas a Administração além disso sancionou a Lei 12.527/2011 que estabelece algumas diretrizes de acesso a informação pública e dentre essas diretrizes temos: "o fomento ao desenvolvimento da cultura de transparência na administração pública”, isso é um indicativo que a Administração Pública está buscando melhorar no sentido de dar acesso as suas ações para que assim seja possível criar uma cultura de controle social.

Continuando foi perguntado aos entrevistados se a instituição onde eles trabalham buscam a excelência no atendimento ao cidadão/cliente, para 45,5\% concordam parcialmente e 27,3\% concordam plenamente, já 8,9\% se mostraram neutro com relação à afirmação, com relação aos que discordam desta afirmação os que discordam parcialmente e discordam plenamente, somam respectivamente $12,4 \%$ e $5,9 \%$ respectivamente.

Para finalizar este segmento foi indagado aos entrevistados sobre à tomada de decisões e como eles classificariam a instituição onde eles trabalham, se eram centralizadas ou descentralizadas, com isso, 66,8\% entendem que com relação à tomada de decisões a instituição onde trabalham é centralizada, já 33,2\% indicam que suas instituições são descentralizadas. 


\section{Sobre GESPÚBLICA}

Nesta parte dos resultados teremos os questionamentos com relação a percepção dos servidores públicos federais sobre Gespública e foi perguntado se os entrevistados já leram, estudaram ou ouviram a respeito do Decreto 5.378 de 2005 que instituiu o Programa Gespública e o resultado obtido foi que $60,9 \%$ responderam não a respeito à afirmativa e $39,1 \%$ responderam sim, o que indica que a grande maioria desconhecia sobre o Programa Gespública.

Continuando a pesquisa os itens a seguir se referem ao conhecimento dos servidores a respeito dos objetivos estabelecidos para o Programa Gespública e o primeiro questionamento foi se os entrevistados acreditam ser importante para a Administração Pública aumentar a sua capacidade de formulação, implementação e avaliação das suas políticas públicas para que mais pessoas sejam beneficiadas e apresentou o seguinte resultado: $77,7 \%$ dos entrevistados concordam plenamente com a questão e 19,3\% concordam parcialmente, totalizando $97 \%$ de concordância sobre este tema. Foi perguntado também se os entrevistados acreditam ser importante para a Administração Pública promover a eficiência, por meio de melhor aproveitamento dos recursos públicos, para que assim aumente a efetividade de suas ações, o resultado para este questionamento foi: 99,5 concordaram, sendo que $87,6 \%$ concordaram plenamente e 11,9\% concordaram parcialmente. Também com o intuito de aprofundar sobre o conhecimento dos servidores a respeito dos objetivos estabelecidos para o Programa Gespública, foi perguntado a eles se é importante para a Administração Pública promover a gestão democrática, participativa, transparente e ética e o resultado foi o seguinte: $87,6 \%$ concordaram plenamente e 11,4\% concordaram parcialmente, ou seja, de algum modo $99 \%$ concordaram que é importante para a Administração Pública realizar este tipo de promoção. Por conseguinte foi perguntado se os entrevistados acreditam que é importante para a administração pública assegurar a eficácia e efetividade da ação governamental, promovendo a adequação entre meios, ações, impactos e resultados, sendo que $83,7 \%$ concordam plenamente sobre o tema e 15,3\% concordam parcialmente. O importante sobre isto é que é possível identificar o anseio dos servidores com relação a uma Administração Pública moderna, eficiente e que consiga desenvolver suas atividades de forma plena, com técnicas gerenciais que realmente faça com seja possível atingir os objetivos e metas estabelecidos.

Após esses questionamentos foi perguntado aos servidores se eles sabiam que as últimas 4 perguntas se referiam a objetivos estabelecidos ao Programa Gespública e o resultado foi: 
$64,9 \%$ não sabiam e $35,1 \%$ sabiam que as quatro perguntas anteriores se referiam aos objetivos da Gespública. Também foi perguntado se eles acreditavam que em algum momento, tais objetivos foram aplicados na instituição onde eles trabalham, onde: 51\% concordam parcialmente, $7,9 \%$ concordam plenamente, já $16,8 \%$ se mantiveram neutro, $7,4 \%$ discordam parcialmente e $16,8 \%$ discordam plenamente sobre a pergunta.

Seguindo com a pesquisa foi perguntado também se os servidores acreditam que acredita que ações como o Programa Gespública deveriam ser mais difundidas pela administração pública federal e com isso $84,2 \%$ afirmaram que concordam plenamente, $12,9 \%$ concordam parcialmente, demonstrando assim a importância da integração dos servidores nas ações realizados pelo Governo Federal. Tanto que na sequência foi perguntado se ações como a Gespública poderia trazer melhorias para a Administração Pública Federal e para 75,7\% concordam plenamente e 18,8\% concordam parcialmente que ações como Gespública traria melhorias à Administração Pública Federal. Mais uma vez fica evidente que existe uma compreensão e consciência por parte dos servidores que é preciso mudar o estado atual da Administração Pública com resquícios de burocracia, para uma Administração Pública moderna e que utilize os avanços que o mundo moderno trouxeram para a humanidade.

Os dois últimos itens da pesquisa fazem referência sobre o conhecimento dos servidores públicos federais sobre a revogação do decreto $\mathrm{n}^{\circ} .5 .378$ de 2005 que instituiu o programa nacional de gestão pública e desburocratização (Gespública), pelo decreto 9.094 de 17 de julho de 2017 que dispõe sobre a simplificação do atendimento prestado aos usuários dos serviços públicos, dispensando reconhecimento de firma e autenticação em documentos produzidos no país, sendo que $72,3 \%$ dos entrevistados responderam que não sabiam desta revogação e $27,7 \%$ responderam que sim, sabiam sobre a revogação.

Finalizando a pesquisa foi indagado aos servidores se eles acreditam que a decisão sobre a revogação do Programa Gespública por parte da Administração Pública Federal foi acertada, para $19,3 \%$ e 13,4\% discordaram plenamente e discordaram parcialmente, respectivamente, onde acreditam que a Administração Pública Federal não acertou ao revogar o decreto que instituiu o Programa Gespública, os que se mantiveram neutro sobre o tema totalizaram 41,6\% dos entrevistados, e os que concordam parcialmente e concordam plenamente somam, respectivamente, $16,8 \%$ e $8,9 \%$ dos entrevistados. 


\section{Considerações Finais}

Os resultados da pesquisa permite afirmar que na percepção da maioria dos servidores públicos federais entrevistados, não conheciam o decreto que instituiu o Programa Gespública, como também, ficou comprovado que a maioria não sabia a respeito de sua revogação pelo decreto 9.094 de 17 de julho de 2017. Isso significa que a Administração Pública Federal não soube aplicar os princípios e objetivos estabelecidos dentro do Programa Gespública e pouco foi feito com relação a isso.

Mas o que fica marcado dentro desta pesquisa é o anseio dos servidores por um estilo diferente de gestão, como ficou expressado nas questões sobre a instituição que eles atuam, já que a maioria as enxerga como modelos centralizadores de tomada de decisão e isso muitas vezes acarreta problemas e também o enrijecimento da gestão, pois agindo de forma centralizada os gestores não conseguem vislumbrar a capacidade de seus comandados e muito menos as necessidades da instituição que comanda, apesar que através da centralização é possível controlar a instituição de forma mais ampla, pois no serviço público existe uma grande influência de regulamentos e legislação que acabam influenciando pela escolha do método centralizador de gerir, mas conforme Chiavenato (2008): “o foco no cliente e a agilidade no atendimento das necessidades do cliente tem levado muitas organizações a migrar resolutamente para a descentralização", além disso, com a descentralização é possível estimular a independência das pessoas dos níveis mais baixos da organização, ajudando assim a construir uma equipe preparada para atender as necessidades dos clientes/cidadãos, pois descentralizando, todos da organização terão conhecimento do planejamento estratégico e também dos objetivos e metas da instituição, pois ajudaram a criá-los.

Outro ponto a ser destacado é que de forma quase unânime os servidores públicos federais, concordaram que os objetivos traçados pelo Programa Gespública, seriam importantes para a Administração pública, o que demonstra que os servidores estão atualizados com esta corrente de gestão, onde é possível ser ético e transparente, ao mesmo tempo é preciso vislumbrar que a eficiência tem que estar presente na Administração Pública e que também é preciso exercer uma Gestão participativa onde cada um possa dar sua contribuição para que assim atinjam-se os resultados necessários e efetivos que toda a sociedade almeja.

Mas infelizmente a Administração Pública Federal está no caminho contrário do que se buscava com a instituição do Programa Gespública, já que simplesmente o programa foi 
revogado por um decreto que tem como objeto: "a dispensa de reconhecimento de firma e de autenticação em documentos produzidos no país e institui a Carta de Serviços ao usuário", sendo que este último já se fazia presente no decreto da Gespública. Essa medida não teve nenhum tipo de discussão com as instituições que fazem parte da Administração Pública Federal, o governo de forma centralizadora, tomou a decisão sem consultar, para saber como poderia resolver as distopias do programa e a partir daí tomar medidas que trouxessem o efeito necessário tanto para a gestão pública quanto para todos os "stakeholders".

Com isso é preciso analisar friamente o que teremos pela frente, pois o discurso liberal que vem surgindo com muita força no nosso país poderá acarretar tempos tenebrosos para o Estado Brasileiro, pois a visão geral da sociedade é que o que é público é totalmente ineficiente, corrupto e não entrega o que a sociedade precisa e a partir disso não se pensa mais num modelo gerencial para a Administração Pública, mas simplesmente acredita-se que com menos Estado, a sociedade estará no caminho certo para o fim de todas as desigualdades existentes no país. Mas na verdade é preciso buscar o equilíbrio entre o público e o privado, pois caso seja necessário, deve-se reduzir o quantitativo de empresas públicas que só dão prejuízo e que poderiam ser privatizadas ou extintas, para que assim se possa focar no que realmente traga o retorno esperado, também se faz necessário aplicar Administração Pública Gerencial de forma mais concreta, saindo definitivamente das amarras da Burocracia, pois como ficou demonstrado na pesquisa, o servidor público federal, que é o capital intelectual da Administração Pública, tem grande anseio por mudanças na sua gestão e acredita que seja possível realizar essa transição, onde teremos um Estado Brasileiro diferente do que temos atualmente, sendo eficaz nas suas ações, priorizando a eficiência do uso dos bens e do erário e efetivamente atendendo as necessidades da sua população.

\section{Referências:}

ABRUCIO, Fernando Luiz. O impacto do modelo gerencial na administração pública: Um breve estudo sobre a experiência internacional recente, 1997, 52 p. (Cadernos ENAP; n. 10) ISSN: 0104-7078

BRESSER PEREIRA, L. C. Da administração pública burocrática à gerencial. Revista do Serviço Público, v. 120, n.1, 1996.

BRASIL. Decreto no 5.378 de 23 de fevereiro de 2005. Diário Oficial da União, Poder Executivo, Brasília, DF, 24 de fev. 2005. Seção 1, p. 2. 
. Decreto no 9.094, de 17 de julho de 2017. Diário Oficial da União, Poder Executivo, Brasília, DF, 18 de jul. 2017. Seção 1, p. 2.

Lei $\mathbf{n}^{\mathbf{0}}$ 12.527, de 18 de novembro de 2011. Diário Oficial da União, Poder Executivo, Brasília, DF, 18 de nov. 2011. Seção 1, p. 1.

. MINISTÉRIO DO PLANEJAMENTO, ORÇAMENTO E GESTÃO. Secretaria de Gestão. Programa Nacional de Gestão Pública e Desburocratização - GESPÚBLICA: Cadernos GESPÚBLICA - Documento de referência - Ciclo 2006. Brasília: MP/SEGES, 2002.

MINISTÉRIO DO PLANEJAMENTO, ORÇAMENTO E GESTÃO. Secretaria de Gestão Pública. Programa GESPÚBLICA, Modelo de Excelência em Gestão Pública, Brasília; MP, SEGEP, 2014.

PRESIDÊNCIA DA REPÚBLICA. Plano Diretor da Reforma do Aparelho do Estado. Brasília: Presidência da República, Câmara da Reforma do Estado. Ministério da Administração Federal e Reforma do Estado, 1995.

CHIAVENATO, Idalberto. Administração Geral e Pública / Idalberto Chiavenato. - 2 ed. - Rio de Janeiro: Elsevier, 2008.

Introdução à Teoria Geral de Administração. 6 ed. - Rio de Janeiro: Campus, 2000.

PALUDO, Augustinho Vicente. Administração Pública. - 5 ed. rev., atual. e ampl. - Rio de Janeiro: Forense; São Paulo: MÉTODO, 2016.

UNIVERSIDADE FEDERAL DO VALE DO SÃO FRANCISCO. Gabinete da Reitoria. Sistema Integrado de Bibliotecas. Manual de normalização de trabalhos acadêmicos da UNIVASF/ UNIVASF. - 3. ed. - Petrolina, 2016.

VASCONCELOS Coutinho, MARCELO James. Administração pública voltada para o cidadão: quadro teórico-conceitual. In: Revista do Serviço Público, Brasília, ano 51, nº 03, Julho / Setembro, 2000, 4173.

ZANELLA, Liane Carly Hermes. Metodologia de estudo e de pesquisa em administração - 2. ed. reimp. - Florianópolis: Departamento de Ciências da Administração / UFSC, 2012.

\section{Como citar este artigo (Formato ABNT):}

RABELO NETO, Miguel Lino Spinelli; LIMA FILHO, Raimundo Nonato. Percepção dos Servidores Públicos Federais Sobre o Programa Nacional de Gestão Pública e Desburocratização GESPÚBLICA. Id on Line Rev.Mult. Psic., 2018, vol.12, n.40, p.172-185. ISSN: 1981-1179. 